\title{
Demand elasticity predicts addiction endophenotypes and the therapeutic efficacy of an orexin/hypocretin-1 receptor antagonist in rats
}

\author{
Morgan H. James ${ }^{1,2}$, Hannah E. Bowrey ${ }^{1,3}$, Colin M. Stopper ${ }^{1}$, Gary Aston-Jones ${ }^{1}$ \\ ${ }^{1}$ Brain Health Institute, Rutgers University and Rutgers Biomedical and Health Sciences, 683 \\ Hoes Lane West, Piscataway, NJ 08854, USA \\ ${ }^{2}$ The Florey Institute of Neuroscience and Mental Health, Parkville, Vic, Australia \\ ${ }^{3}$ Save Sight Institute, The University of Sydney, Sydney, NSW, Australia
}

\section{Abstract}

\begin{abstract}
Behavioral economics is a powerful, translational approach for measuring drug demand in both humans and animals. Here, we asked if demand for cocaine in rats with limited drug experience could be used to identify individuals most at risk of expressing an addiction phenotype following either long- or intermittent access self-administration schedules, both of which model the transition to uncontrolled drug-seeking. Because the orexin-1 receptor antagonist SB-334867 (SB) is particularly effective at reducing drug-seeking in highly motivated individuals, we also asked whether demand measured after prolonged drug experience could predict SB efficacy. Demand elasticity (a) measured immediately following acquisition of cocaine self-administration ('baseline $a$ ') was positively correlated with $a$ assessed after $2 \mathrm{w}$ of long- or intermittent access. Baseline $a$ also predicted the magnitude of compulsive responding for cocaine, drug-seeking in initial abstinence and cued reinstatement following long-, intermittent- or standard short access. When demand was measured after these differential access conditions, a predicted the same addiction endophenotypes predicted by baseline $a$, as well as primed reinstatement and the emergence of negative emotional mood behavior following abstinence. $a$ also predicted the efficacy of SB, such that high demand rats showed greater reductions in motivation for cocaine following SB compared to low demand rats. Together, these findings indicate that a might serve as a behavioral biomarker to predict individuals most likely to progress from controlled to uncontrolled drug use, and to identify individuals most likely to benefit from orexin-based therapies for the treatment of addiction.
\end{abstract}

Correspondence: Morgan H. James, Brain Health Institute, as above. morgan.james@ rutgers.edu.

Author contributions

MHJ, HEB, CMS and GAJ designed the experiments. MHJ, HEB and CMS collected the behavioral data. MHJ analyzed the data. MHJ, HEB and GAJ wrote the paper. All authors provided critical feedback on the manuscript draft.

Conflict of interest

All authors report no competing financial interests.

Data accessibility

Data are available upon request from the corresponding author. 


\section{Keywords}

behavioral economics; extended access; intermittent access; long access; reinstatement

\section{Introduction}

A major goal of addiction medicine is to identify those individuals at greatest risk of progressing from controlled to compulsive drug use, such that preventative and therapeutic measures can be targeted in an efficient manner (Blanchard et al., 2009; Belin et al., 2011). To this end, preclinical studies have sought to identify behavioral biomarkers that predict addiction vulnerability. Rodents with high locomotor reactivity to a novel environment, or a high propensity to visit a new environment in a free-choice procedure, show a greater tendency to exhibit addiction-like behaviors when given the opportunity to self-administer drugs of abuse (Davis et al., 2008; Blanchard et al., 2009; Belin et al., 2011; Flagel et al., 2016). Although these models provide a useful tool for examining addiction vulnerability in rats, the extent to which these phenotyping procedures can be applied to clinical populations is unclear.

Behavioral economics (BE) has emerged as a promising cross-species paradigm for determining addiction propensity (Bentzley et al., 2013, 2014; MacKillop et al., 2018). A fundamental construct of $\mathrm{BE}$ is demand, or the amount of commodity that is sought or consumed at a given price. Demand for drugs can be measured via a hypothetical purchasing task in humans (MacKillop et al., 2008, 2010, 2018) or an operant task in rodents (Oleson et al., 2011; Bentzley et al., 2013, 2014). Demand elasticity (denoted as alpha; a) refers to the extent to which demand is sensitive to changes in price, and can be modeled in both humans and rodents using identical mathematical approaches (Hursh \& Silberberg, 2008; Bentzley et al., 2013, 2014). In humans, a predicts several clinical outcomes across various drugs of abuse, including cocaine (MacKillop et al., 2008, 2010, 2012, 2018; Bruner \& Johnson, 2014). In animals, we and others have shown that $a$ is correlated with a range of addictionlike behaviors, including compulsive drug taking, drug-seeking during initial abstinence and reinstatement propensity (Bentzley et al., 2014). However, in many of these studies, a was determined in subjects already meeting the diagnostic criteria for addiction (human studies) or following extensive drug exposure (rat studies). Ideally, an addiction biomarker could be measured early in the addiction cycle (e.g., during recreational use) and be used to predict individuals most at risk of progressing to more problematic drug use behavior. Thus, here we sought to determine whether $a$, as assessed in rats after only limited drug exposure, can predict those individuals most at risk of transitioning to compulsive drug seekers after more drug exposure. To do this, we analyzed data from a number of studies carried out in our laboratory whereby 'baseline $a$ ' was measured in rats immediately following the acquisition of cocaine self-administration behavior but prior to rats being exposed to either long or intermittent self-administration schedules, both of which model the transition to uncontrolled drug-seeking (Ahmed \& Koob, 1998; Zimmer et al., 2012; Allain et al., 2015; Kawa et al., 2016; James \& Aston-Jones, 2017; James et al., 2018b). We report that baseline $a$ predicts those individuals that exhibit greater economic demand, compulsive seeking and reinstatement liability following long or intermittent access. Thus, a may serve as a useful 
screening tool to identify individuals that would most benefit from early intervention strategies.

Although a general biomarker might allow for preventative strategies to be more effective and efficient, there will undoubtedly remain a population of individuals who make the transition to uncontrolled drug use and therefore require further intervention. To this end, a biomarker that predicts how an individual might respond to a specific pharmacological treatment would be very useful. A large number of studies now point to the hypothalamic orexin (hypocretin) system as a promising target for pharmacotherapies designed to reduce craving and drug-seeking behavior (James et al., 2012, 2017; Yeoh et al., 2014; Walker \& Lawrence, 2017; Campbell et al., 2018; Perrey \& Zhang, 2018). Orexin peptides act at two receptors, orexin receptor 1 and 2 (OxR1, OxR2); studies generally support a dichotomy of function with respect to OxR1 vs. OxR2 signaling, with OxR1 mediating motivational processes and OxR2 being more important in governing sleep/wake function (Sakurai, 2007; James et al., 2017; Brodnik et al., 2018). Consistent with this, OxR1 antagonists reduce seeking of various drugs of abuse, particularly when high levels of effort are required to obtain the drug, or when motivation for drug reward is enhanced by external stimuli such as stress or drug-related cues (Mahler et al., 2014; James et al., 2017). However, several reports indicate that there is significant individual variability in responsivity to OxR1 antagonists, such that the greatest effects are observed in individuals with high baseline intake or motivation for drug (Lawrence et al., 2006; Moorman \& Aston-Jones, 2009; Jupp et al., 2011; Bentzley \& Aston-Jones, 2015; Lopez et al., 2016; Moorman et al., 2017; James et al., 2018b). These observations led us to hypothesize that motivation for drug, as assessed by the behavioral economics paradigm, could also predict those individuals most likely to respond to the antidrug-seeking properties of the commonly used OxR1 antagonist SB- 334867 (SB). Thus, in a second set of analyses, we analyzed data from several studies carried out in our laboratory where a for cocaine was determined prior to treatment with SB. We show that the anti-drug-seeking effects of SB are stronger in animals with higher economic demand for cocaine, indicating that a could also be used as a biomarker to direct pharmacological treatment in a clinical setting.

\section{Materials and methods}

\section{Subjects}

Male Sprague-Dawley rats (Charles River, Raleigh, NC and Kingston, NY, 300 g, 6-8 weeks of age upon arrival) were single-housed under a reverse 12:12 h light cycle in a temperature- and humidity-controlled facility. Food and water were provided ad libitum. For all behavioral experiments, rats were tested during their dark (active) cycle at the same time each day. Here, we present data from a total of 87 rats collected over several experiments that were conducted between January 2015 and January 2018; other data arising from these experiments are presented elsewhere (James et al., 2018b). All experiments were approved by the Rutgers University Institutional Animal Care and Use Committee, and were conducted according to specifications of the Guide for the care and use of laboratory animals (National Research Council, 2011). 
Drugs

Cocaine $\mathrm{HCl}$ powder was provided by the National Institute of Drug Abuse (NIDA;

Research Triangle Park, NC, USA) and was dissolved in sterile saline. SB-334867 (SB)

[1-(2-methylbenzoxazol-6-yl)-3-[1,5]naphthyridin-4-yl urea hydrochloride; provided by NIDA] was suspended in 2\% dimethylsulfoxide and 10\% 2-hydroxypropyl-b-cyclodextrin (Sigma) in sterile water; 0,10 or $30 \mathrm{mg} / \mathrm{kg}$ was given in a volume of $4 \mathrm{ml} / \mathrm{kg}$ (i.p.) $30 \mathrm{~min}$ prior to testing. SB has 50-fold selectivity for OX1R over OX2R and 100-fold selectivity over approximately 50 other molecular targets (Porter et al., 2001; Smart et al., 2001).

\section{Jugular catheter surgery and cocaine self-administration training}

Jugular catheter surgery was performed as previously described (James et al., 2016; McGlinchey et al., 2016). Briefly, animals were anesthetized with isoflurane (1-3\% with a flow rate of $2 \mathrm{~L} / \mathrm{min}$ ) and received an analgesic (rimadyl, $5 \mathrm{mg} / \mathrm{kg}$, s.c.). Chronic indwelling catheters were inserted into the right jugular vein, which exited the body via a port between the scapulae. Beginning 1 day after surgery, animals received daily prophylactic i.v. cefazolin $(10 \mathrm{mg})$ and heparin (10U) daily intravenously via the catheter; this continued throughout self-administration training. Rats were allowed 1 week recovery before commencing self-administration training.

Rats were trained to self-administer cocaine in sound-attenuated operant boxes with two retractable levers (Med Associates) under a fixed-ratio 1 (FR1) schedule. The house light was illuminated and active lever presses resulted in a delivery of $3.6 \mathrm{~s}$ infusion of cocaine (dose; i.v.) paired with a tone and light stimulus above the active lever. A $20 \mathrm{~s} \mathrm{time} \mathrm{out}$ period was signaled following each infusion by the turning off of the house light, during which time active lever responses no longer resulted in an infusion of cocaine. Responses on the inactive lever had no scheduled consequences but were recorded. Rats trained in $2 \mathrm{~h}$ sessions for at least 6 days, until they achieved stable cocaine consumption ( $>10$ infusions, $<20 \%$ variability) across 3 days (McGlinchey et al., 2016; James et al., 2018a).

\section{Economic demand procedure and demand curve fitting}

We used a within-session behavioral economics paradigm, previously described elsewhere (Bentzley et al., 2013, 2014). Briefly, using an FR1 schedule, rats received access to decreasing doses of cocaine in successive 10 min intervals on a quarter logarithmic scale $(383.5,215.6,121.3,68.2,38.3,21.6,12.1,6.8,3.8,2.2$ and $1.2 \mu \mathrm{g} /$ infusion) over $110 \mathrm{~min}$ sessions. For the duration of each infusion, the houselight was turned off and light + tone cues were presented; active lever responses did not result in further infusions during this period.

An exponential demand equation (Hursh \& Silberberg, 2008) was fit to each animal's data from each session. From the resulting demand curves, we extracted $a$ (demand elasticity, or the rate of consumption decline with increasing price), and $\mathrm{Q}_{0}$ (drug consumption at null cost). a represents an intrinsic property of the drug's motivational efficacy that is independent of the animal's s peferred drug consumption at null cost $\left(\mathrm{Q}_{0}\right)$ (Hursh \& Silberberg, 2008; Bentzley et al., 2013, 2014). 
Rats were tested on the BE paradigm for a minimum of 6 days and until stability of $a$ and $\mathrm{Q}_{0}$ was achieved ( $<25 \%$ variability over 3 consecutive days). This provided an index of 'baseline' demand for cocaine; rats were tested in exactly the same manner following differential access conditions, described below.

\section{Intermittent, long and short access self-administration paradigms}

Animals were randomly allocated to short- $(\mathrm{ShA})$, long- $(\mathrm{LgA})$ or intermittent- (IntA) access groups. ShA and $\mathrm{LgA}$ rats were given continuous access to cocaine for $1 \mathrm{~h}$ or $6 \mathrm{~h}$, respectively, for 14 days (Ahmed \& Koob, 1998). The sessions were identical to selfadministration FR1 training in terms of cocaine dose, schedule of reinforcement, light and tone presentation and time out periods. IntA rats were also given 14 days of selfadministration; however in these sessions, cocaine was available in a 5 min access period (signaled by house light on, levers extended), followed by a 25 min cocaine non-availability period (lights out, levers retracted); this was repeated over a 6-h session (total $1 \mathrm{~h}$ access to cocaine). As per previous studies (Zimmer et al., 2012), cocaine infusions were brief ( $1 \mathrm{~s}$; $0.055 \mathrm{mg}$ ) and were paired with light + tone cues. No timeout periods were imposed during the 5-min epochs when cocaine was available, apart from the time during which the pump was active. The return of cocaine availability following each 25 -min period of cocaine nonavailability was signaled by the presentation of the light + tone cues for $5 \mathrm{~s}$ and a single priming injection of cocaine $(1 \mathrm{~s}, 0.055 \mathrm{mg})$ before the levers were reinserted into the operant chamber. Some animals included in the SB analyses were trained on the ShA and IntA paradigms as above, however training sessions were separated by 1-4 days (average of 1 session every 2 days).

\section{Test of compulsive (punished) responding for cocaine}

A punished responding task (Bentzley et al., 2014) was used to test rats for compulsive drugseeking behavior. Animals were allowed to adjust to a relatively high cocaine infusion dose ( $0.38 \mathrm{mg}$ cocaine in a $2.6 \mathrm{~s}$ iv infusion) over at least three sessions, and until the number of infusions earned per session was stable ( $<20 \%$ variation). Throughout the test session, an identical cocaine dose was held constant, but infusions were paired with shocks of increasing amplitude. Footshock was omitted for the first two 10-min bins, however, commencing in the third bin, shocks were delivered during each cocaine infusion and these increased in amplitude every $10 \mathrm{~min}$ on a tenth- $\log _{10}$ scale: $0.13,0.16,0.20,0.25,0.32,0.40$, $0.50,0.63$ and 0.79 milliamps (mA). Throughout the session, shock resistance was defined as the maximum cumulative charge in millicoulombs $(\mathrm{mC})$ a rat self-administered in any one bin.

\section{Extinction and reinstatement testing}

Extinction training and reinstatement testing occurred in 2-h sessions in the same operant chambers as were used for self-administration training. In extinction training, lever responding was extinguished in daily sessions in which the active lever responses no longer resulted in a cocaine infusion, nor light+tone presentation. Extinction training continued for at least 7 days and until rats met a criterion of $<25$ active lever responses over 3 consecutive days (McGlinchey et al., 2016; James et al., 2018a). We tested cued reinstatement behavior where light+tone cues were presented in the absence of cocaine. This occurred once at the 
beginning of the session and then again in response to active lever responses. To assess primed reinstatement behavior, rats were given a priming dose of cocaine $(10 \mathrm{mg} / \mathrm{kg}$, i.p. $)$ immediately prior to being placed in the operant chamber. Animals were tested under extinction conditions. For both cued and primed reinstatement tests, rats underwent three tests to test the effect of SB at 10 and $30 \mathrm{mg} / \mathrm{kg}$ (and vehicle); only data collected under vehicle conditions were analyzed here (effects of SB on reinstatement are reported elsewhere (James et al., 2018b)). Between reinstatement tests, rats received at least two additional extinction sessions, and continued until they met a criteria of $<25$ active lever presses over 2 days.

\section{Open field test}

To evaluate anxiety-like behavior, rats were positioned in a clear acrylic open field apparatus $(42 \times 42 \times 30 \mathrm{~cm})$. The apparatus was equipped with SuperFlex monitors (Omintech Electronics Inc, Columbus, $\mathrm{OH}$ ) containing two $16 \times 16$ infrared light beam arrays: one to measure horizontal activity and another to measure vertical activity. Locomotor activity was recorded by Fusion SuperFlex software. The amount of time spent within an $8 \times 8$ square matrix in the center of the chamber was determined over a period of $15 \mathrm{~min}$.

\section{Saccharin preference test}

Rats were habituated to two bottles over 2 consecutive days. During this period, one bottle containing a sweet $0.1 \%$ saccharin solution and the other containing water, were placed in the rat' $s$ home cage. The location of the bottles was counterbalanced and was interchanged every $12 \mathrm{~h}$. The following day at the peak of the animals' active period (noon), the two bottles were re-introduced to the cage for a total of $2 \mathrm{~h}$, with the locations of each bottle swapped after $1 \mathrm{~h}$ (test day 1 ). This same procedure was repeated the following day (test day 2). Preference for saccharin was determined by calculating the amount of saccharin consumed as a percentage of total liquid intake. Saccharin preference scores were averaged across both test days for each animal.

\section{Forced swim test}

Animals were placed in a cylindrical Plexiglas tank $(38.5 \mathrm{~cm}$ high $\times 30.5 \mathrm{~cm}$ diameter; INSTECH) filled with warm water $\left(25^{\circ} \mathrm{C}\right)$. Pretesting occurred on the first day for $15 \mathrm{~min}$ and testing occurred $24 \mathrm{~h}$ later for $5 \mathrm{~min}$. A digital video camera mounted over the tank recorded behaviors during both FSTs. Each animal was scored offline on a computer monitor by an observer blind to the experimental conditions of the animals for swimming, climbing and immobility behaviors, as described elsewhere (Gonzalez \& Aston- Jones, 2008).

\section{Experimental overview}

Experiment 1-Animals underwent FR1 self-administration training (mean $=6.36$ days, $\mathrm{SD}=1.22$ days, range 6-11 days) before being tested on the behavioral economics procedure to determine baseline demand for cocaine. Animals were then given LgA, IntA or ShA to cocaine for 14 days, after which they were tested on the BE paradigm again to examine the effect of these differential access conditions on cocaine demand. Previous 
studies demonstrated that baseline demand measures remain stable over weeks (Bentzley et al., 2014), a finding confirmed here in ShA animals (see below). Here, we focus our analyses on demand scores from the first session following ShA, LgA or IntA, as this timepoint is associated with the most pronounced changes in the LgA group (James et al., 2018b); using these data allowed us to best assess the demand paradigm as a predictor of LgA-induced changes in addiction behavior. Rats underwent testing for compulsive (punished) responding, and then extinction training, followed by tests of cued- or primed reinstatement behavior. A subgroup of rats was then subjected to $4 \mathrm{w}$ homecage abstinence, during which time they were left undisturbed except for weekly cage changes. These rats were then tested on the SPT, OFT and FST (in this order), with at least 5 days separating each test. Other results arising from these experiments are reported elsewhere (James et al., 2018b).

Experiment 2-Animals were assessed for baseline demand, subjected to LgA, IntA or ShA procedures, and then re-tested for demand as above. Following stabilization of demand ( 7 days; denoted 'a [post-LgA,IntA,ShA]'), rats were tested for cocaine demand following injections of SB $(0,10,30 \mathrm{mg} / \mathrm{kg}$; i.p., order counterbalanced). Approximately, half of animals $(n=44)$ included in these analyses were also included as part of Experiment 1 - SB testing took place prior to testing for compulsive responding.

\section{Statistical analyses}

All analyses were carried out using Prism GraphPad and SigmaPlot V14.0. For all analyses, a values were normalized using log transformation. All correlations depict transformed a values; in some instances (Fig. 1j-1), raw a values are presented for clarity. Changes in demand following $\mathrm{LgA}$, IntA or ShA across populations were compared using pairedsamples $t$-tests. Changes in demand in high vs. low demand populations were assessed first by a median split of baseline a values (lower a values $=$ high demand group; higher a values = low demand group), and then analyzed using a 2 group (high demand, low demand) $\times 2$ time (pre-, post-LgA, IntA, ShA) mixed model ANOVA with Bonferroni post hoc comparisons. All correlations were carried out using tests of Pearson's correlation coefficients. Across all correlations, three data points were excluded as they were identified as outliers by Prism auto-detection software. For SB analyses, overall change in a values following SB treatment was assessed across the population using paired-samples $t$-tests relative to vehicle treatment. The population was then divided into high-, intermediate- and low-demand groups using a quartile split of a values under vehicle; efficacy of SB (calculated as percentage change in a values relative to vehicle) was then compared across both doses using a repeated-measures ANOVA. An a value of 0.05 was adopted for all tests. All analyses used two-tailed tests.

\section{Results}

\section{Baseline economic demand is an effective biomarker for predicting those individuals most likely to exhibit greater addiction-like behavior following $\operatorname{LgA}$ or IntA}

Both LgA and IntA to cocaine have been reported to enhance drug motivation. To quantify this change in motivation, we measured demand elasticity for cocaine before and after long 
or intermittent access. On the first day following $\operatorname{LgA}$, rats exhibited significantly lower a values compared to baseline - reflecting greater drug motivation - as indicated by a leftward shift in the distribution of a values ( $t_{26}=2.633, P=0.0140$; Fig. 1a). We observed an even stronger decrease in a values following IntA compared to baseline values $\left(t_{23}=6.928, P<\right.$ 0.0001 ; Fig. 1b). Consistent with previous reports, there was no change in motivation for cocaine (a values) following ShA ( $t_{28}=0.6392, P=0.5281$; Fig. $\left.1 \mathrm{c}\right)$. Together, these data indicate that both $\operatorname{LgA}$ and IntA increase motivation for cocaine and thus serve as effective models to study the transition from controlled to compulsive drug-seeking. Representative demand curves from LgA, IntA and ShA rats are shown in Fig. 1d-f. A more thorough comparison of changes in demand following LgA and IntA is described in (James et al., 2018b).

We next asked whether baseline $a$ values can be used to predict those animals most likely to exhibit high motivation for cocaine following $\operatorname{LgA}$ or IntA. Baseline a values were positively correlated with $a$ values following both $\operatorname{LgA}\left(R^{2}=0.2626, P=0.0063\right.$; Fig. $\left.1 \mathrm{~g}\right)$ or IntA $\left(R^{2}=0.3056, P=0.0051\right.$; Fig. $\left.1 \mathrm{~h}\right)$, indicating that those animals that exhibited greater demand for cocaine following only limited drug exposure were more likely to transition to a higher demand state following $\mathrm{LgA}$ or IntA. Despite there being no change in a values following ShA, we saw a strong correlation between pre- and post-ShA a values $\left(R^{2}=0.9619, P<0.0001 ;\right.$ Fig. 1 i) $)$ indicating that demand elasticity is extremely stable across time (in this case 2 weeks) in individuals with limited drug experience, pointing to the reliability of the $\mathrm{BE}$ approach as a behavioral biomarker.

To further probe the predictive nature of baseline a values, we carried out a median split on baseline a values across all access groups to derive 'high risk' (high demand; HD) and 'low risk' (low demand; LD) groups, as might be done clinically. Interestingly, HD rats did not exhibit an overall change in demand following $\mathrm{LgA}$, whereas $\mathrm{LgA}$ was associated with a significant decrease in a (increase in motivation) in LD rats (group $\times$ time interaction $F_{1,25}$ $=15.97, P=0.0005)$. Post-LgA a values tended to be lower in HD compared to LD rats $(P=$ 0.1070; Fig. 1j), indicating that those individuals identified as 'at risk' at baseline may continue to exhibit a higher motivation for cocaine following extended cocaine access. In IntA animals, both $\mathrm{HD}(P=0.0016)$ and $\mathrm{LD}(P<0.0001)$ rats exhibited a significant change in a values (main effect of 'time' $F_{1,22}=54.12, P<0.0001$ ). Those rats identified as HD at baseline had lower a (higher motivation) than baseline LD animals following IntA ( $P=$ 0.0345; Fig. 1k). Interestingly, there was a small decrease in a following ShA in the LD group (group x time interaction $F_{1,26}=6.833, P=0.0147$, Bonferroni post hoc comparison $P$ $=0.0304$ ), indicating that even limited access to cocaine can increase motivation for cocaine in animals that initially exhibit low demand for drug early in the addiction cycle (Fig. 11).

\section{Baseline economic demand predicts some addiction-like behaviors following LgA or IntA}

Next, we tested whether baseline a values can predict other DSM-V-relevant addiction behaviors following longer drug exposure (i.e., 2 weeks of $\mathrm{LgA}$, IntA or ShA). Baseline a values were negatively correlated with the maximum electric charge animals accepted to maintain stable brain-cocaine concentrations $\left(R^{2}=0.2105, P=0.0161\right.$; Fig. 2a), indicating that animals with higher baseline demand for cocaine exhibited greater levels of compulsive 
drug-seeking following $\mathrm{LgA}$, IntA or ShA. Baseline a values were also negatively correlated with the amount of drug-seeking (responses on the active lever) on the first day of extinction $\left(R^{2}=0.1339, P=0.0013\right.$; Fig. $\left.2 \mathrm{~b}\right)$ or cued reinstatement of extinguished responding $\left(R^{2}=\right.$ $0.2497, P=0.0016$; Fig. $2 \mathrm{c})$, but did not predict primed reinstatement responding $\left(R^{2}=\right.$ $0.0710, P=0.1548$; Fig. 2d). Baseline a values did not predict negative emotional-like behavior on the saccharin preference $\left(R^{2}=0.0715, P=0.2996\right.$; Fig. $\left.2 \mathrm{e}\right)$ or forced swim $\left(R^{2}\right.$ $=0.3269, P=0.5754$; Fig. 2f) tests, which were conducted following 4 weeks of homecage abstinence.

\section{Economic demand following $\mathrm{LgA}$ or IntA serves as a strong biomarker for addiction-like behaviors and negative emotional behavior following abstinence}

Next, we tested whether a values derived from BE testing after $\mathrm{LgA}$, IntA or ShA provide a better prediction of drug-relevant behaviors than baseline $a$ values. There was a strong negative correlation between post-LgA/IntA/ShA a values and compulsive responding $\left(R^{2}=\right.$ $0.3158, P=0.0023$; Fig. 3a) or drug-seeking during initial abstinence $\left(R^{2}=0.3822, P<\right.$ 0.0001; Fig. 3b); these correlations were stronger than those using baseline values (described immediately above). Post-LgA/IntA/ShA a values were also highly predictive of both cued $\left(R^{2}=0.2793, P=0.008\right.$; Fig. $\left.3 \mathrm{c}\right)$ and primed $\left(R^{2}=0.2588, P=0.0041\right.$; Fig. $\left.3 \mathrm{~d}\right)$ reinstatement behavior. Moreover, unlike baseline $a$ values, post-LgA/IntA/ShA $a$ values were positively correlated with saccharin preference $\left(R^{2}=0.4777, P=0.0021\right.$; Fig. $\left.3 \mathrm{e}\right)$ and negatively correlated with immobility on the forced swim test $\left(R^{2}=0.2845, P=0.0026\right.$; Fig. $3 \mathrm{f}$ ), indicating that animals with higher motivation for cocaine following $\mathrm{LgA}$, IntA or ShA exhibited greater anhedonia- and despair-like behavior, respectively, following forced abstinence.

\section{Economic demand following LgA or IntA predicts the anti-addiction efficacy of the orexin-1 receptor antagonist SB-334867}

We and others have previously reported that blockade of OxR1 signaling with SB reduces high-effort responding for cocaine, especially in animals that exhibit high baseline responding for drug. Thus, here we tested whether the efficacy of SB at reducing cocaine demand (at two doses; 10 and $30 \mathrm{mg} / \mathrm{kg}$ ) can be predicted by post- $\mathrm{LgA} / \mathrm{IntA} / \mathrm{ShA} a$ values. Across a large population of animals (SB10, $n=82$; SB30 $n=87)$ animals, both SB10 $\left(\mathrm{t}_{81}=\right.$ $3.376, P=0.0011$; Fig. $4 \mathrm{a})$ and SB3( $t_{86}=5.232, P<0.0001$; Fig. $\left.4 \mathrm{~b}\right)$ were associated with a significant rightward shift in a values, indicating greater elasticity in demand for cocaine (lower motivation). Representative demand curves from an animal treated with vehicle, SB10 and SB30 are presented in Fig. 4c (Veh vs. SB10) and 4d (Veh vs. SB30). Interestingly, there was a strong negative relationship between post-LgA/IntA/ShA $a$ values and the efficacy of SB10 $\left(R^{2}=0.1508, P=0.0003\right.$; Fig. 4e $)$ and SB30 $\left(R^{2}=0.1364, P=\right.$ 0.0004; Fig. 4f), indicating that animals with greater demand for cocaine (lower a values) exhibited the greatest reductions in demand elasticity following treatment with both doses of SB.

To further explore this relationship, we divided the total population by their post-LgA/ IntA/ShA a values to identify HD (top quartile), intermediate demand (ID; middle two quartiles) and LD (bottom quartile) groups; we then assessed the efficacy of SB (10 or 30 
$\mathrm{mg} / \mathrm{kg}$, ip) across these different populations. In HD animals, SB10 and SB30 were equally efficacious in reducing demand (increasing a) for cocaine $\left(F_{2,59}=7.353, P=0.002\right.$; Fig. 5a). In ID animals, both SB10 and SB30 treatment was associated with a significant increase in demand elasticity (decreased motivation; $F_{2}, 132=9.999, P<0.001$ ) and this effect was stronger for SB30 ( $P<0.001$ vs. vehicle; Fig. 5b). In LD animals, neither SB10 nor SB30 treatment was associated with a change in $a\left(F_{2,62}=0.445, P=0.644\right)$.

\section{Discussion}

We report three key findings relating to the use of economic demand as a behavioral biomarker for addiction. First, we show that baseline a (demand elasticity) measured after only limited drug exposure predicts the extent to which rats will exhibit excessive motivation for cocaine following cocaine access paradigms that promote the transition to uncontrolled drug use (LgA or IntA). Moreover, this 'baseline' measure of economic demand also predicts an individual's propensity to exhibit compulsive (punished) drug-seeking, as well as seeking during abstinence or in response to drug stimuli, following $\operatorname{LgA}$ or IntA. Second, we show that a reassessment of $a$ following these cocaine abuse paradigms provides an even stronger biomarker for addiction-related endophenotypes, including the emergence of negative emotional behavior following abstinence. Finally, a values strongly predict the extent to which the orexin-1 antagonist, SB, reduces motivation for cocaine, such that SB is more efficacious in high demand (low a) animals but has only limited utility in low demand (high $a$ ) animals. Together, these data indicate that economic demand analysis, which is readily applied in humans, may serve as a powerful clinical tool to identify individuals most at risk of progressing from recreational to compulsive drug use, and to identify those most likely to show therapeutic benefit from treatment with an orexin-1 receptor antagonist.

\section{Demand elasticity as a biomarker for addiction propensity}

We previously reported a strong relationship between economic demand and several addiction-related behaviors in rats, including compulsive drug taking and relapse-like behavior (Bentzley et al., 2014). Similarly, measures of demand derived from a hypothetical purchasing task predict real-world cocaine use in cocaine-dependent patients (Bruner \& Johnson, 2014). Parallel findings have been found in studies involving heavy tobacco (MacKillop et al., 2008, 2012; Murphy et al., 2011) and alcohol (Murphy \& MacKillop, 2006; Murphy et al., 2009; MacKillop et al., 2010; Gray \& MacKillop, 2014) users in relation to demand and severity of substance misuse and dependence. Here, we extend these findings to show that economic demand assessment may also be used as a preemptive diagnostic tool to identify individuals most at risk of developing substance use disorder. Rats with a high baseline demand for cocaine assessed after only limited drug exposure went on to exhibit greater motivation (lower $a$ values) following $\operatorname{LgA}$ or IntA, and there was a strong correlation between baseline demand and the extent to which rats exhibited compulsive drug-seeking and cued reinstatement behavior following $\operatorname{LgA}$ or IntA. This was despite the greatest relative changes in demand occurring in individuals identified as having low baseline demand for cocaine; indeed only a modest change in demand was observed in HD animals after IntA, whereas no change occurred in HD animals following LgA. Interestingly, LD rats exhibited a modest increase in motivation for cocaine (lower a values) after ShA, 
indicating that even individuals identified as having low risk of cocaine abuse are susceptible to the motivation-enhancing properties of limited (in terms of amount) but extended (in terms of time) cocaine exposure.

Consistent with previous reports in animals (Bentzley et al., 2014) and clinical populations (MacKillop et al., 2008, 2010, 2012), a values derived after the transition to compulsive drug use are an even more robust biomarker of addiction endophenotypes. Indeed, post-LgA/ IntA/ShA $a$ values predicted compulsive drug-seeking, seeking during initial abstinence and cued reinstatement of extinguished seeking to a stronger extent than baseline $a$ values. In addition, post-LgA/IntA/ShA $a$ values predicted primed reinstatement levels, as well as the expression of anhedonia- and despair-like behavior following withdrawal. This may indicate that although trait factors contribute substantially to addiction-like vulnerability, ultimately this vulnerability reflects combination of both trait and state factors (O'Brien, 2008).

\section{Comparison with other behavioral biomarkers of addiction}

Many studies have identified different patterns of drug-related behavior in animals that exhibit differential reactivity and/or preference to novel environments. For example, rats that exhibit greater locomotor reactivity to a novel inescapable environment (high responder phenotype; HR) learn to self-administer cocaine at a faster rate, have higher rates of drug intake, and are more reactive to the locomotor-activating effects of psychostimulants, compared to their low responder (LR) littermates (Piazza et al., 1989; Davis et al., 2008; Blanchard et al., 2009). Following extended cocaine access, HR rats exhibit persistent cocaine-seeking (seeking during a nondrug-available period) and increased reinstatement of extinguished cocaine-seeking; these rats also exhibit distinct epigenetic modifications in the nucleus accumbens core that are not observed in LR rats (Flagel et al., 2016). An alternative model identifies rats that develop a strong conditioned place preference for a novel environment (high-novelty-preferring phenotype; HNP; Belin et al., 2011). These HNP rats show a greater severity of cocaine addiction-like behavior across a number of DSM-Vrelevant criteria, including persistence in drug-seeking (measured by drug-seeking during periods when drug is unavailable), compulsive (punished) responding for drug and motivation for drug (measured on a progressive ratio schedule) (Belin et al., 2011).

Efforts to 'reverse translate' the HR/HNP models to clinical populations using tests of unconditioned motoric activity have had some success; however, the link between exploratory behavior in humans and psychiatric disorders, including addiction, remains to be fully understood (Young et al., 2016). In contrast, the behavioral economics approach described here provides a direct mathematical link between addiction-like behavior in rats and humans (Hursh \& Silberberg, 2008; Bentzley et al., 2013, 2014), so that preclinical findings using this approach can be readily translated to the clinic. An interesting feature of HNP/HR models is that they can predict addiction-like behavior prior to drug use. However, individuals most in need of preventative interventions are likely to present to relevant health care providers following some level of recreational drug use, perhaps at the direction of law enforcement. Our findings indicate that this may be an ideal timepoint to employ a behavioral economic approach to assess an individual's likelihood to progress to more problematic patterns of drug-taking, and to allocate interventional resources as appropriate. 
In contrast, assessment of motoric activity at this timepoint might be contaminated by previous drug use, as drugs of abuse (psychostimulants in particular) are known to produce long-lasting plasticity in motor systems (Pierce \& Kalivas, 1997). Finally, it is unclear to what extent the HR/HNP models can predict the emergence of negative emotional behavior following drug withdrawal. In fact, in experiments not focused on drug behavior, HR rats are less prone to depression-like behavior compared to LR controls (Clinton et al., 2011; Stedenfeld et al., 2011). In contrast, we show that animals with high demand for cocaine following the transition to compulsive drug use (but not prior) are more likely to score higher on two depression-like behavioral endophenotypes. Given the strong link between negative emotional state and relapse (Koob \& Le Moal, 2008; Koob, 2009), long-term abstinence is likely to be enhanced by identifying those patients most likely to benefit from strategies designed to manage any comorbid depression. In sum, the economic demand approach offers a powerful alternative to the HR/HNP models for predicting addiction vulnerability in individuals with a history of drug use. Future studies that investigate the extent to which the HR, HNP and HD phenotypes overlap with one another, both in terms of behavioral (addiction) and genetic phenotypes, will be of great interest.

\section{Demand elasticity as a predictor of SB efficacy}

We demonstrate that economic demand is also an effective tool for predicting the therapeutic efficacy of the OX1R antagonist SB. We found that demand elasticity for cocaine following $\mathrm{LgA}$, IntA or ShA was directly related to the extent to which SB reduced this measure of motivation for cocaine, such that SB was most effective in high demand animals at both doses tested. Interestingly, animals that fell into the top quartile of demand (lowest a values) were equally responsive to SB10 and SB30, whereas neither dose was effective at reducing drug motivation in bottom-quartile rats. These observations align with several studies that show that SB is more effective at blocking drug-seeking in animals that exhibit high baseline responding for drug. For example, lower doses of SB are more effective at reducing demand and reinstatement behavior in animals that exhibit an addiction multiphenotype following IntA (James et al., 2018b). Moreover, SB reduces ethanol self-administration and reinstatement selectively in rats that show high preference for alcohol in a two-bottle choice test (Moorman \& Aston-Jones, 2009) or greater operant responding for alcohol on an escalating fixed ratio schedule (Moorman et al., 2017). Similar findings have been reported in alcohol-preferring mice using an OX1R antagonist (Lopez et al., 2016), as well as in selectively bred alcohol-preferring rats (Lawrence et al., 2006; Jupp et al., 2011). Our findings are also consistent with several studies that have reported that the magnitude of Fos expression in orexin neurons during drug-seeking is positively correlated with drug-seeking behavior (Harris et al., 2005; Hamlin et al., 2007; Richardson \& Aston-Jones, 2012; Moorman et al., 2016). Together with these reports, our analyses indicate that the orexin system may be particularly strongly engaged during drug-seeking in high demand animals. Indeed, we recently reported that the number and activity of orexin-expressing neurons is higher in animals that exhibit high demand for cocaine following IntA (James et al., 2018b). Similarly, enhanced orexin expression has been reported in brains of human heroin addicts (Thannickal et al., 2018) and in alcohol-preferring rats following chronic alcohol intake (Lawrence et al., 2006). Differences in orexin system function in high demand animals 
might also be associated with greater receptor densities in key reward regions or enhanced receptor binding; further studies are required to test these possibilities.

SB is widely used to test the role of OxR1 vs. OxR2 in reward seeking. Importantly however, selectivity of SB for OxR1 over OxR2 is modest ( 50 fold selectivity), and SB has some affinity for several other GPCRs, including serotonin (5HT) $2 \mathrm{~B}$ and $2 \mathrm{C}$ receptors (Porter et al., 2001; Smart et al., 2001; Perrey et al., 2018). Thus, based on SB studies alone, it is difficult to completely rule out the potential contribution of OxR2 (or 5HT receptors) in results obtained. Several compounds with greater selectivity for OxR1 have been developed, and a small number of studies indicate that these compounds recapitulate the effects of SB on drug-seeking behavior (Lopez et al., 2016; Levy et al., 2017). Dual-orexin receptor antagonists have also been reported to have antidrug-seeking properties (Srinivasan et al., 2012; Steiner et al., 2013; Anderson et al., 2014), including suvorexant, a compound that has the major advantage of being FDA-approved for the treatment of insomnia (Gentile et al., 2017a,b; Simmons et al., 2017). Thus, further work is required to fully understand the utility of single vs. dual-orexin receptor antagonists for the treatment of addiction (Khoo \& Brown, 2014; Yeoh et al., 2014). Regardless, our findings indicate that the economic demand task may be an effective means to identify individuals with pathological drug motivation that are most likely to benefit from these therapies. The ability to direct personalized pharmacotherapy to high demand individuals is especially important, as these individuals typically have poor clinical outcomes following psychotherapy-based interventions (Murphy et al., 2015).

\section{Conclusions}

In conclusion, we show that demand elasticity (a), measured using our within-session behavioral economics task after only limited drug-taking experience, is a behavioral biomarker of an individual animal's propensity to develop several addiction-like endophenotypes following $\mathrm{LgA}$ or IntA to cocaine. Re-assessment of demand elasticity after $\mathrm{LgA}$ or IntA serves as a strong predictor of future drug-seeking and the emergence of negative emotional behavior during withdrawal. Moreover, the behavioral economic approach can also identify individuals most likely to respond to the anti-addiction properties of an OX1R antagonist. Given that the economic demand model has been validated in cocaine-dependent patients (Bruner \& Johnson, 2014), future studies to translate such findings into clinical populations may help and guide toward more effective and efficient treatment for cocaine use disorder.

\section{Acknowledgements}

This work was supported by C.J. Martin Fellowships from the National Health and Medical Research Council of Australia to MHJ (No. 1072706) and HEB (No. 1128089), by a U.S. Public Health Service award from the National Institute of Drug Abuse to GAJ (R01 DA006214), and by the Charlotte and Murray Strongwater Endowment for Neuroscience and Brain Health (GAJ). We would like to gratefully acknowledge Ms. Nikki Koll and Ms. Shayna O'Connor for their excellent assistance with the behavioral experiments, as well as Ms. Nupur Jain for her general assistance. 


\section{Abbreviations}

BE

SB

$\operatorname{LgA}$

ShA

IntA

HR

LR

HNP

LNP

HD

LD

ID behavioral economics

SB-334867

long access

short access

intermittent access

high responder

low responder

high novelty-preferring

low novelty-preferring

high demand

low demand

intermediate demand

\section{References}

Ahmed SH \& Koob GF (1998) Transition from moderate to excessive drug intake: change in hedonic set point. Science, 282, 298-300. [PubMed: 9765157]

Allain F, Minogianis E-A, Roberts DCS \& Samaha A-N (2015) How fast and how often: the pharmacokinetics of drug use are decisive in addiction. Neurosci. Biobehav. R, 56, 166-179.

Anderson RI, Becker HC, Adams BL, Jesudason CD \& Rorick-Kehn LM (2014) Orexin-1 and orexin-2 receptor antagonists reduce ethanol self-administration in high-drinking rodent models. Front Neurosci, 8, 33. [PubMed: 24616657]

Belin D, Berson N, Balado E, Piazza PV \& Deroche-Gamonet V (2011) High-novelty-preference rats are predisposed to compulsive cocaine self-administration. Neuropsychopharmacology, 36, 569579. [PubMed: 20980989]

Bentzley BS \& Aston-Jones G (2015) Orexin-1 receptor signaling increases motivation for cocaineassociated cues. Eur. J. Neurosci, 41, 1149-1156. [PubMed: 25754681]

Bentzley BS, Fender KM \& Aston-Jones G (2013) The behavioral economics of drug selfadministration: a review and new analytical approach for within-session procedures. Psychopharmacology, 226, 113-125. [PubMed: 23086021]

Bentzley BS, Jhou TC \& Aston-Jones G (2014) Economic demand predicts addiction-like behavior and therapeutic efficacy of oxytocin in the rat. Proc. Natl Acad. Sci. USA, 111, 11822-11827. [PubMed: 25071176]

Blanchard MM, Mendelsohn D \& Stamp JA (2009) The HR/LR model: further evidence as an animal model of sensation seeking. Neurosci. Biobehav. R, 33, 1145-1154.

Brodnik ZD, Alonso IP, Xu W, Zhang Y, Kortagere S \& España RA (2018) Hypocretin receptor 1 involvement in cocaine-associated behavior: therapeutic potential and novel mechanistic insights. Brain Res. 10.1016/j.brainres.2018.07.027 [Epub ahead of print].

Bruner NR \& Johnson MW (2014) Demand curves for hypothetical cocaine in cocaine-dependent individuals. Psychopharmacology, 231, 889-897. [PubMed: 24217899]

Campbell EJ, Marchant NJ \& Lawrence AJ (2018) A sleeping giant: suvorexant for the treatment of alcohol use disorder? Brain Res. 10.1016/j.brainres.2018.08.005 [Epub ahead of print]. 
Clinton SM, Stead JD, Miller S, Watson SJ \& Akil H (2011) Developmental underpinnings of differences in rodent novelty-seeking and emotional reactivity. Eur. J. Neurosci, 34, 994-1005. [PubMed: 21864320]

Davis BA, Clinton SM, Akil H \& Becker JB (2008) The effects of novelty-seeking phenotypes and sex differences on acquisition of cocaine self-administration in selectively bred High-Responder and Low-Responder rats. Pharmacol. Biochem. Behav, 90, 331-338. [PubMed: 18445506]

Flagel SB, Chaudhury S, Waselus M, Kelly R, Sewani S, Clinton SM, Thompson RC, Watson SJ Jr et al. (2016) Genetic background and epigenetic modifications in the core of the nucleus accumbens predict addiction-like behavior in a rat model. Proc. Natl Acad. Sci. USA, 113, E2861-E2870. [PubMed: 27114539]

Gentile TA, Simmons SJ, Barker DJ, Shaw JK, Espana RA \& Muschamp JW (2017a) Suvorexant, an orexin/hypocretin receptor antagonist, attenuates motivational and hedonic properties of cocaine. Addict. Biol., 23, 247-255. [PubMed: 28419646]

Gentile TA, Simmons SJ, Watson MN, Connelly KL, Brailoiu E, Zhang Y \& Muschamp JW (2017b) Effects of suvorexant, a dual orexin/hypocretin receptor antagonist, on impulsive behavior associated with cocaine. Neuropsychopharmacology, 43, 1001-1009. [PubMed: 28741623]

Gonzalez MM \& Aston-Jones G (2008) Light deprivation damages monoamine neurons and produces a depressive behavioral phenotype in rats. Proc. Natl Acad. Sci. USA, 105, 4898-4903. [PubMed: 18347342]

Gray J \& MacKillop J (2014) Interrelationships among individual differences in alcohol demand, impulsivity, and alcohol misuse. Psychol. Addict. Behav, 28, 282-287. [PubMed: 23915370]

Hamlin AS, Newby J \& McNally GP (2007) The neural correlates and role of D1 dopamine receptors in renewal of extinguished alcohol-seeking. Neuroscience, 146, 525-536. [PubMed: 17360123]

Harris GC, Wimmer M \& Aston-Jones G (2005) A role for lateral hypothalamic orexin neurons in reward seeking. Nature, 437, 556-559. [PubMed: 16100511]

Hursh SR \& Silberberg A (2008) Economic demand and essential value. Psychol. Rev, 115, 186-198. [PubMed: 18211190]

James MH \& Aston-Jones G (2017) Orexin/hypocretin, central amygdala, and escalation of cocaine intake. Biol. Psychiat, 81, 552-553. [PubMed: 28283054]

James MH, Yeoh JW, Graham BA \& Dayas CV (2012) Insights for developing pharmacological treatments for psychostimulant relapse targeting hypothalamic peptide systems. J Addict. Res. Ther, S4, 008.

James MH, Quinn RK, Ong LK, Levi EM, Smith DW, Dickson PW \& Dayas CV (2016) Rapamycin reduces motivated responding for cocaine and alters GluA1 expression in the ventral but not dorsal striatum. Eur. J. Pharmacol, 784, 147-154. [PubMed: 27181066]

James MH, Mahler SV, Moorman DE \& Aston-Jones G (2017) A decade of orexin/hypocretin and addiction: where are we now? Curr. Top Behav. Neurosci, 33, 247-281. [PubMed: 28012090]

James MH, McGlinchey EM, Vattikonda A, Mahler SV \& Aston- Jones G (2018a) Cued reinstatement of cocaine but not sucrose seeking is dependent on dopamine signaling in prelimbic cortex and is associated with recruitment of prelimbic neurons that project to contralateral nucleus accumbens core. Int. J. Neuropsychoph, 21, 89-94.

James MH, Stopper CM, Zimmer BA, Koll NE, Bowrey HE \& Aston-Jones G (2019) Increased number and activity of a lateral subpopulation of hypothalamic orexin/hypocretin neurons underlies the expression of an addicted state in rats. Biol. Psychiat. 85, 925-935. [PubMed: 30219208]

Jupp B, Krivdic B, Krstew E \& Lawrence AJ (2011) The orexin(1) receptor antagonist SB-334867 dissociates the motivational properties of alcohol and sucrose in rats. Brain Res, 1391, 54-59. [PubMed: 21439948]

Kawa AB, Bentzley BS \& Robinson TE (2016) Less is more: prolonged intermittent access cocaine self-administration produces incentive-sensitization and addiction-like behavior. Psychopharmacology, 233, 3587-3602. [PubMed: 27481050]

Khoo SY \& Brown RM (2014) Orexin/hypocretin based pharmacotherapies for the treatment of addiction: DORA or SORA? CNS Drugs, 28, 713-730. [PubMed: 24942635] 
Koob GF (2009) Neurobiological substrates for the dark side of compulsivity in addiction. Neuropharmacology, 56(Suppl. 1), 18-31. [PubMed: 18725236]

Koob GF \& Le Moal M (2008) Review. Neurobiological mechanisms for opponent motivational processes in addiction. Philos. T. R. Soc. Lon. B, 363, 3113-3123.

Lawrence AJ, Cowen MS, Yang HJ, Chen F \& Oldfield B (2006) The orexin system regulates alcoholseeking in rats. Brit. J. Pharmacol, 148, 752-759. [PubMed: 16751790]

Levy KA, Brodnik ZD, Shaw JK, Perrey DA, Zhang Y \& España RA (2017) Hypocretin receptor 1 blockade produces bimodal modulation of cocaine-associated mesolimbic dopamine signaling. Psychopharmacology, 234, 2761-2776. [PubMed: 28667509]

Lopez MF, Moorman DE, Aston-Jones G \& Becker HC (2016) The highly selective orexin/hypocretin 1 receptor antagonist GSK1059865 potently reduces ethanol drinking in ethanol dependent mice. Brain Res, 1636, 74-80. [PubMed: 26851547]

MacKillop J, Murphy JG, Ray LA, Eisenberg DT, Lisman SA, Lum JK \& Wilson DS (2008) Further validation of a cigarette purchase task for assessing the relative reinforcing efficacy of nicotine in college smokers. Exp. Clin. Psychopharm, 16, 57-65.

MacKillop J, Miranda R, Monti PM, Ray LA, Murphy JG, Rohse-now DJ, McGeary JE, Swift RM et al. (2010) Alcohol demand, delayed reward discounting, and craving in relation to drinking and alcohol use disorders. J. Abnorm. Psychol, 119, 106-114. [PubMed: 20141247]

MacKillop J, Brown CL, Stojek MK, Murphy CM, Sweet L \& Niaura RS (2012) Behavioral economic analysis of withdrawal- and cueelicited craving for tobacco: an initial investigation. Nicotine Tob. Res, 14, 1426-1434. [PubMed: 22416117]

MacKillop J, Goldenson NI, Kirkpatrick MG \& Leventhal AM (2019) Validation of a behavioral economic purchase task for assessing drug abuse liability. Addict. Biol, 24, 303-314. [PubMed: 29314376]

Mahler SV, Moorman DE, Smith RJ, James MH \& Aston-Jones G (2014) Motivational activation: a unifying hypothesis of orexin/hypocretin function. Nat. Neurosci, 17, 1298-1303. [PubMed: 25254979]

McGlinchey EM, James MH, Mahler SV, Pantazis C \& Aston-Jones G (2016) Prelimbic to accumbens core pathway is recruited in a dopamine-dependent manner to drive cued reinstatement of cocaine seeking. J. Neurosci, 36, 8700-8711. [PubMed: 27535915]

Moorman DE \& Aston-Jones G (2009) Orexin-1 receptor antagonism decreases ethanol consumption and preference selectively in high-ethanol-preferring Sprague-Dawley rats. Alcohol, 43, 379-386. [PubMed: 19671464]

Moorman DE, James MH, Kilroy EA \& Aston-Jones G (2016) Orexin/hypocretin neuron activation is correlated with alcohol seeking and preference in a topographically specific manner. Eur. J. Neurosci, 43, 710-720. [PubMed: 26750264]

Moorman DE, James MH, Kilroy EA \& Aston-Jones G (2017) Orexin/hypocretin-1 receptor antagonism reduces ethanol self-administration and reinstatement selectively in highly-motivated rats. Brain Res, 1654, 34-42. [PubMed: 27771284]

Murphy JG \& MacKillop J (2006) Relative reinforcing efficacy of alcohol among college student drinkers. Exp. Clin. Psychopharm, 14, 219-227.

Murphy JG, MacKillop J, Skidmore JR \& Pederson AA (2009) Reliability and validity of a demand curve measure of alcohol reinforcement. Exp. Clin. Psychopharm, 17, 396-404.

Murphy JG, MacKillop J, Tidey JW, Brazil LA \& Colby SM (2011) Validity of a demand curve measure of nicotine reinforcement with adolescent smokers. Drug Alcohol Depen, 113, 207-214.

Murphy JG, Dennhardt AA, Yurasek AM, Skidmore JR, Martens MP, MacKillop J \& McDevittMurphy ME (2015) Behavioral economic predictors of brief alcohol intervention outcomes. J. Consult. Clin. Psych, 83, 1033-1043.

National Research Council. (2011) Guide for the Care and Use of Laboratory Animals, 8th Edn. The National Academies Press, Washington, DC.

O’Brien CP (2008) Review. Evidence-based treatments of addiction. Philos. T. R. Soc. Lon. B, 363, 3277-3286. 
Oleson EB, Richardson JM \& Roberts DC (2011) A novel IV cocaine self-administration procedure in rats: differential effects of dopamine, serotonin, and GABA drug pre-treatments on cocaine consumption and maximal price paid. Psychopharmacology, 214, 567-577. [PubMed: 21110008]

Perrey DA \& Zhang Y (2018) Therapeutics development for addiction: orexin-1 receptor antagonists. Brain Res. 10.1016/j.brainres.2018.08.025 [Epub ahead of print].

Perrey DA, Decker AM \& Zhang Y (2018) Synthesis and evaluation of orexin-1 receptor antagonists with improved solubility and CNS permeability. ACS Chem. Neurosci, 9, 587-602. [PubMed: 29129052]

Piazza P, Deminiere J, Le Moal M \& Simon H (1989) Factors that predict individual vulnerability to amphetamine self-administration. Science, 245, 1511-1513. [PubMed: 2781295]

Pierce RC \& Kalivas PW (1997) A circuitry model of the expression of behavioral sensitization to amphetamine-like psychostimulants. Brain Res. Brain Res. Rev, 25, 192-216. [PubMed: 9403138]

Porter RA, Chan WN, Coulton S, Johns A, Hadley MS, Widdowson K, Jerman JC, Brough SJ et al. (2001) 1,3-Biarylureas as selective non-peptide antagonists of the orexin-1 receptor. Bioorg. Med. Chem. Lett, 11, 1907-1910. [PubMed: 11459658]

Richardson KA \& Aston-Jones G (2012) Lateral hypothalamic orexin/hypocretin neurons that project to ventral tegmental area are differentially activated with morphine preference. J. Neurosci, 32, 3809-3817. [PubMed: 22423101]

Sakurai T (2007) The neural circuit of orexin (hypocretin): maintaining sleep and wakefulness. Nat. Rev. Neurosci, 8, 171-181. [PubMed: 17299454]

Simmons SJ, Martorana R, Philogene-Khalid H, Tran FH, Gentile TA, Xu X, Su S, Rawls SM et al. (2017) Role of hypocretin/orexin receptor blockade on drug-taking and ultrasonic vocalizations (USVs) associated with low-effort self-administration of cathinone-derived 3,4methylenedioxypyro-valerone (MDPV) in rats. Psychopharmacology, 234, 3207-3215. [PubMed: 28786030]

Smart D, Sabido-David C, Brough SJ, Jewitt F, Johns A, Porter RA \& Jerman JC (2001) SB-334867A: the first selective orexin-1 receptor antagonist. Brit. J. Pharmacol, 132, 1179-1182. [PubMed: 11250867]

Srinivasan S, Simms JA, Nielsen CK, Lieske SP, Bito-Onon JJ, Yi H, Hopf FW, Bonci A et al. (2012) The dual orexin/hypocretin receptor antagonist, almorexant, in the ventral tegmental area attenuates ethanol self-administration. PLoS ONE, 7, e44726. [PubMed: 23028593]

Stedenfeld KA, Clinton SM, Kerman IA, Akil H, Watson SJ \& Sved AF (2011) Novelty-seeking behavior predicts vulnerability in a rodent model of depression. Physiol. Behav, 103, 210-216. [PubMed: 21303678]

Steiner MA, Lecourt H \& Jenck F (2013) The dual orexin receptor antagonist almorexant, alone and in combination with morphine, cocaine and amphetamine, on conditioned place preference and locomotor sensitization in the rat. Int. J. Neuropsychoph, 16, 417-432.

Thannickal TC, John J, Shan L, Swaab DF, Wu MF, Ramanathan L, McGregor R, Chew KT et al. (2018) Opiates increase the number of hypocretin-producing cells in human and mouse brain and reverse cataplexy in a mouse model of narcolepsy. Sci. Transl. Med, 10, eaao4953. [PubMed: 29950444]

Walker LC \& Lawrence AJ (2017) The role of orexins/hypocretins in alcohol use and abuse. Curr. Top Behav. Neurosci, 33, 221-246. [PubMed: 27909991]

Yeoh JW, Campbell EJ, James MH, Graham BA \& Dayas CV (2014) Orexin antagonists for neuropsychiatric disease: progress and potential pitfalls. Front. Neurosci, 8, 36. [PubMed: 24616658]

Young JW, Minassian A \& Geyer MA (2016). Locomotor profiling from rodents to the clinic and back again In Robbins TW \& Sahakian BJ (Eds), Translational Neuropsychopharmacology. Springer International Publishing, Cham, Switzerland, pp. 287-303.

Zimmer BA, Oleson EB \& Roberts DCS (2012) The motivation to self-administer is increased after a history of spiking brain levels of cocaine. Neuropsychopharmacology, 37, 1901-1910. [PubMed: 22453139] 

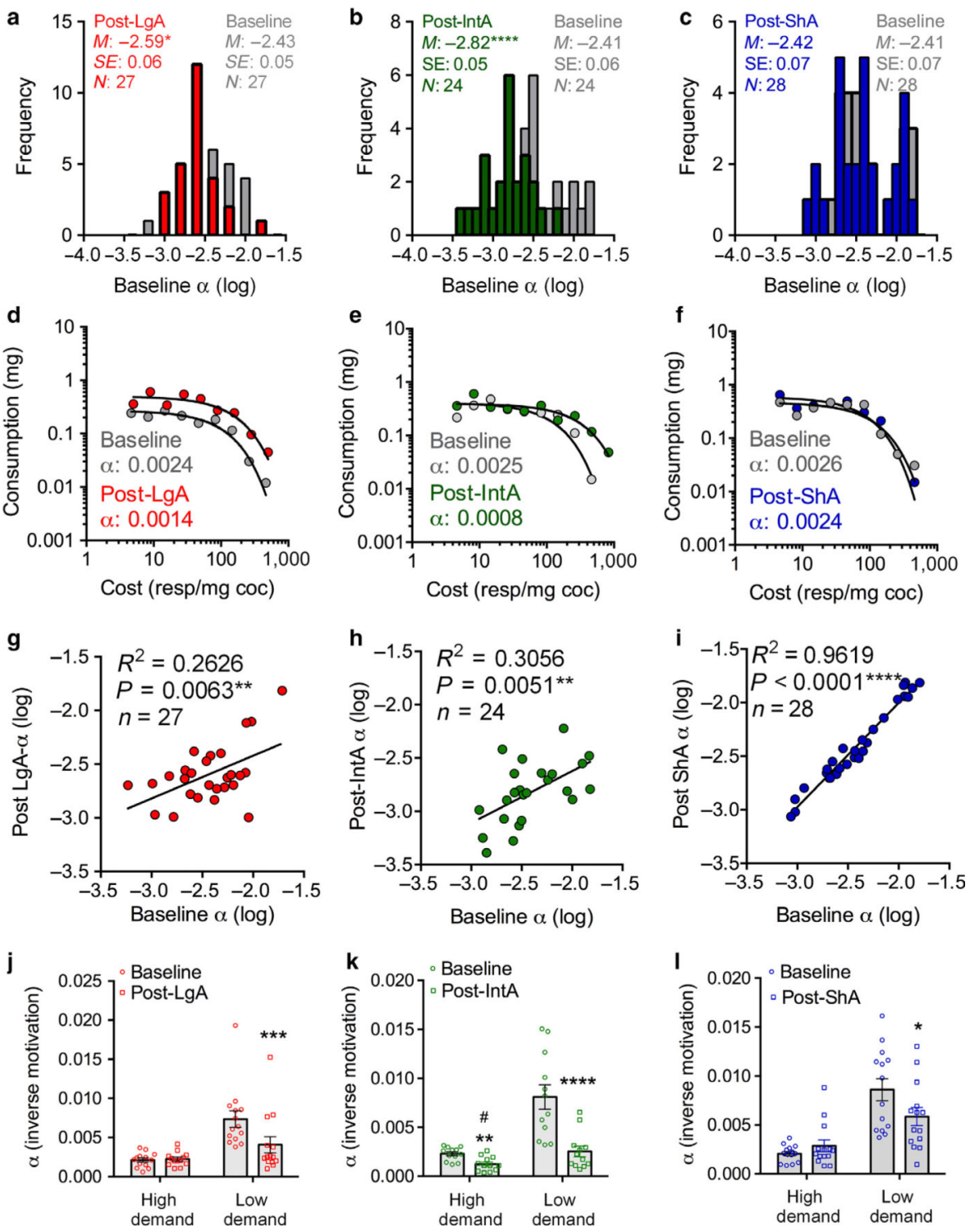

Fig. 1.

Baseline demand predicts motivation for cocaine following long ( $\operatorname{LgA})$ or intermittent (IntA) access. $(a, b)$ Frequency histogram of a values following limited cocaine experience ('baseline'; gray) and following $\operatorname{LgA}$ (red; a) or IntA (green; b) in the same animals. a values are significantly shifted toward the left following $\operatorname{LgA}$ or IntA, indicating lower demand elasticity (higher motivation) for cocaine. Note that this shift is more pronounced for IntA than for $\operatorname{LgA}$ animals. (c) Frequency histogram depicting no change in a values from pre- (gray) to post- (blue) ShA. (d, e, f) Representative demand curves from single animals that underwent either LgA (d), IntA (e) or ShA (f) training. (g, h) Baseline a values predicted a values following $\operatorname{LgA}$ (a) or IntA (b), indicating that animals with the highest demand for cocaine at baseline went on to have the highest demand for cocaine following a transition to compulsive drug-seeking. (i) Pre- and post-ShA a values were also correlated; because there was no shift in demand following ShA, this relationship indicates that demand is highly stable across time (14 days) under normal limited access conditions. (j) Animals 
were split into high- (HD) and low- (LD) demand groups based on a median split of baseline $a$ values. $\mathrm{LgA}$ induced a significant decrease in $a$ values (increased motivation) in LD animals only. Demand tended to be lower in HD animals compared to LD animals following LgA. $* * * P<0.001$ vs. pre-LgA LD. (k) IntA was associated with a significant reduction in $a$ values (increased motivation) in both HD and LD animals. Following IntA, $a$ values were lower in HD animals compared to LD animals. $\# P<0.05$ vs. post-IntA LD. $* * P<0.01$ vs. pre-IntA HD. $* * * * P<0.0001$ vs. pre-IntA LD animals. (1) ShA was associated with a modest decrease in $a$ values in LD animals only. $* P<0.05$ vs. pre-ShA LD. 



f
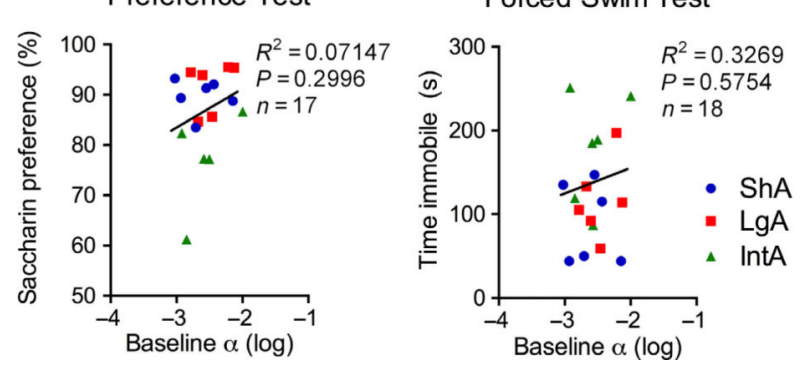

Fig. 2.

Baseline demand predicts compulsive responding for drug and cued reinstatement behavior following $\operatorname{LgA}$, IntA or ShA. (a) Baseline a values were correlated with compulsive responding following $\mathrm{LgA}$ (red), IntA (green) or ShA (blue) training, as assessed by the maximum charge animals were willing to accept in millicoulombs (mC) in an FR1 task where cocaine infusions were paired with footshocks of escalating intensity. Low a (higher motivation) was associated with higher compulsive responding. (b) Baseline $a$ values were also correlated with drug-seeking during initial abstinence (extinction day 1; ED1) following LgA, IntA or ShA. (c) Baseline a values also predicted the extent to which animals exhibited reinstatement of extinguished drug-seeking elicited by drug associated conditioned stimuli (CS+) following LgA, IntA or ShA. (d-f) Baseline $a$ values did not predict cocaine primed reinstatement (d), saccharin preference (e) or time spent immobile on the forced swim test (f) following LgA, IntA or ShA. $* P<0.05, * * P<0.01$. 

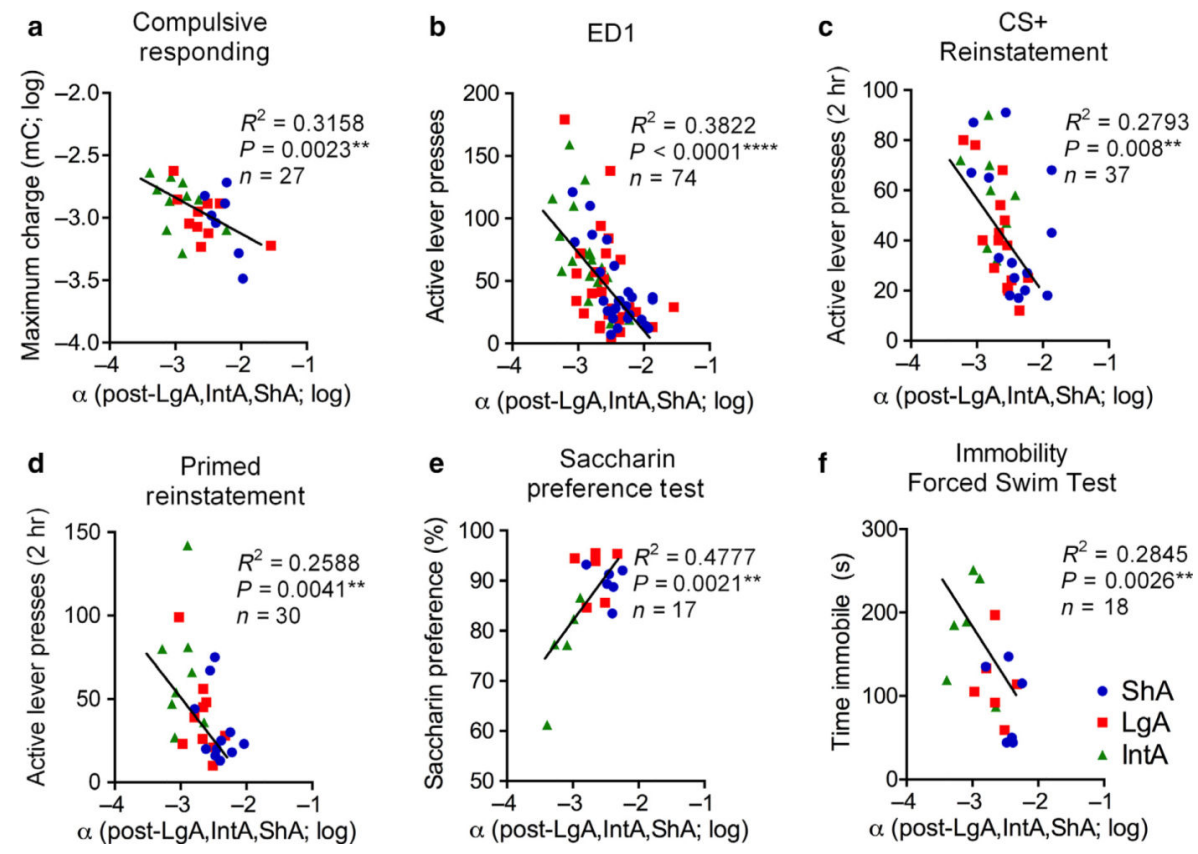

Fig. 3.

Economic demand for cocaine following LgA, IntA or ShA predicts addiction-like behavior and the emergence of negative emotional behavior following abstinence. (a-d) Post-LgA/ IntA/ShA a values were negatively correlated with measures of compulsive responding (a), drug-seeking on the first day of abstinence (b), cued reinstatement (c) and primed reinstatement, such that animals with lower a values (higher demand) scored higher on each of these measures. (e) Post-LgA/IntA/ShA a values were positively correlated with the degree to which animals showed a preference for saccharin on the saccharin preference test following 4 weeks of home cage abstinence. Thus, lower a values (higher demand) were associated with higher withdrawal-induced anhedonia-like behavior. (f) Post-LgA/IntA/ShA a values were negatively correlated with the amount of time spent immobile in the forced swim test following 4 weeks of home cage abstinence. Thus, lower a values (higher demand) were associated with higher withdrawal-induced depression-like behavior. All correlations reflect Pearson's correlation coefficients. ** $P<0.01$. **** $P<0.0001$. 
SB $10 \mathrm{mg} / \mathrm{kg}$

a

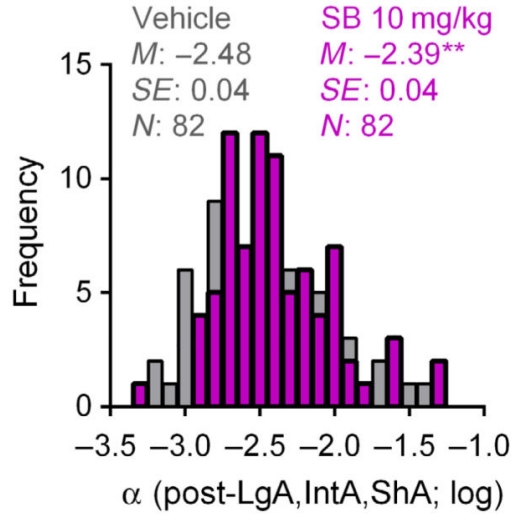

c

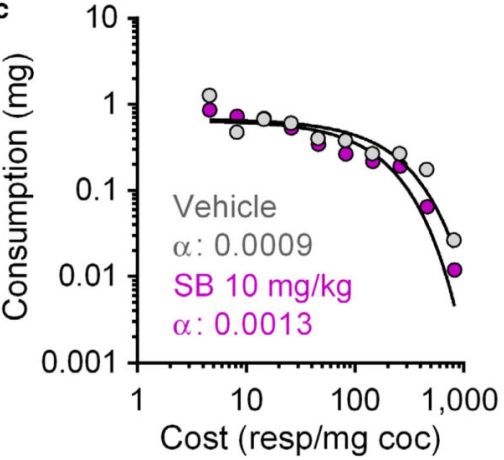

e

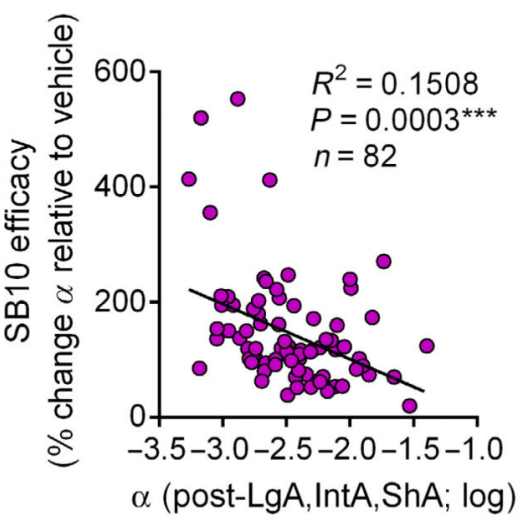

SB $30 \mathrm{mg} / \mathrm{kg}$

b
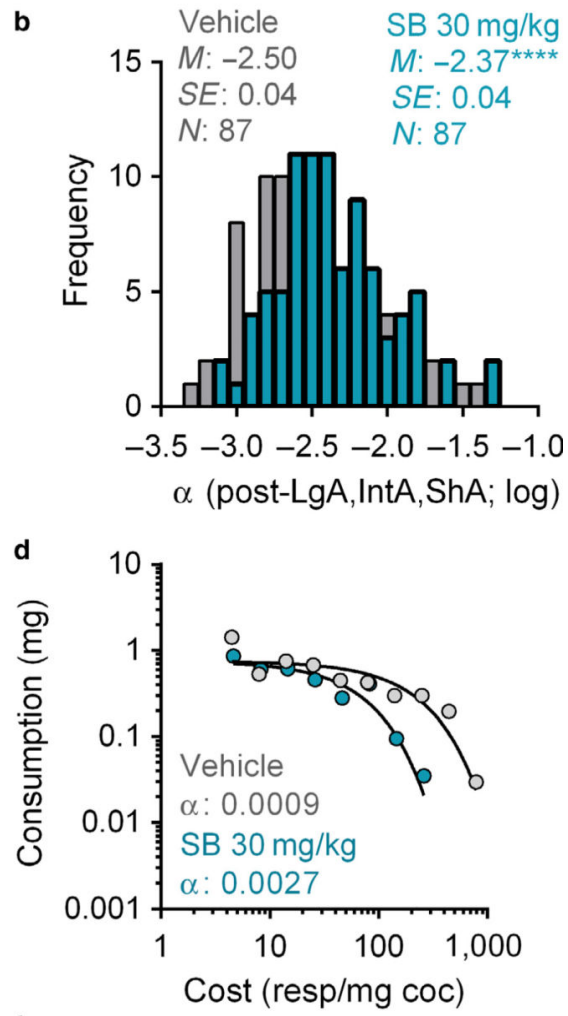

$f$



Fig. 4.

The efficacy of SB in reducing motivation for cocaine is predicted by a values following LgA, IntA or ShA. (a, b) Frequency histogram of a values (log transformed) following vehicle (gray), SB10 (purple; a) or SB30 (blue; b) treatment. Both SB10 and SB30 treatment were associated with a significant rightward shift in $a$ values compared to vehicle treatment, reflecting a decrease in motivation for cocaine. $(c, d)$ Representative demand curves from the same animal following treatment with SB10 (c) and SB30 (d). (e, f) The extent to which SB10 (e) or SB30 (f) increased a values was negatively correlated with a values following $\mathrm{LgA} / \mathrm{IntA} / \mathrm{ShA}$, indicating that animals with the highest demand for cocaine (low a values) were more susceptible to the anti-addiction properties of SB. $* * P<0.01, * * * P<0.001$, $* * * * P<0.0001$. 

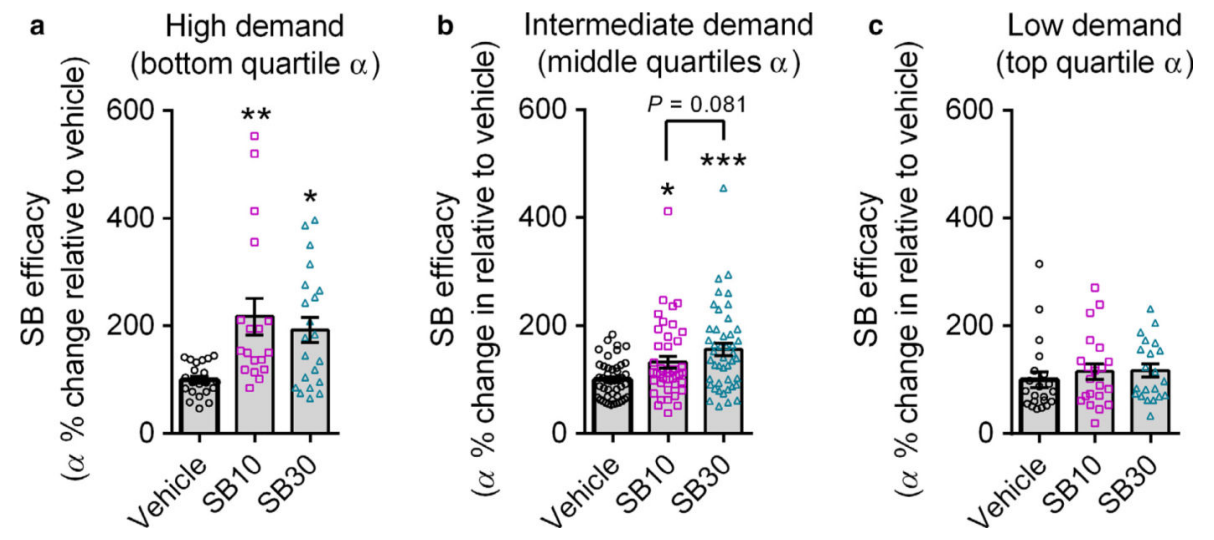

Fig. 5.

SB differentially affects motivation for cocaine in high-, intermediate- and low-demand animals. Animals were divided into high-, intermediate- and low-demand (HD, ID, LD) groups based on a quartile split of demand values derived from BE testing under vehicle conditions. (a) In HD animals, both SB10 $(P=0.003)$ and SB30 $(P=0.010)$ treatments significantly increased $a$ values (decreased motivation) relative to vehicle treatment. There was no significant difference between the efficacy of SB10 and SB30 $(P=0.493)$ in these animals. (b) In ID animals, SB10 $(P=0.022)$ and SB30 $(P<0.001)$ also increased $a$ values (decreased motivation). Despite not reaching significance, there was a strong trend toward this effect being stronger for SB30 compared to SB10 $(P=0.081)$ in these animals. (c) In LD animals, neither SB10 or SB30 affected $a$ values. Data represent mean \pm SEM. All tests represent post hoc Holm-Sidak comparisons. ${ }^{*} P<0.05 . * * P<0.01$. ${ }^{* * *} P<0.001$. 